\title{
HUBUNGAN ANTARA LAMA SAKIT DENGAN STATUS ANTROPOMETRI PASIEN DM TIPE 2 RAWAT JALAN DI RSUD DR. SAIFUL ANWAR MALANG
}

\author{
Ardi Sasongko*, Laksmi Sasiarini* ${ }^{* \star}$ Sri Andarini ${ }^{* \star \star 凶}$
}

\begin{abstract}
Abstrak
Diabetes Mellitus (DM) merupakan masalah kesehatan yang sering ditemukan saat ini di dunia. DM tipe 2 memiliki gejala khas dengan terjadinya penurunan berat badan dan status antropometri pada awal menderita yang dapat mengganggu kualitas hidup penderitanya. Penelitian ini bertujuan untuk mengetahui hubungan antara lama menderita DM tipe 2 dengan status antropometri. Penelitian ini adalah penelitian observational dan pengambilan data dilakukan dengan metode cross sectional. Pengukuran dan pencatatan data dilakukan secara manual dan diuji menggunakan tes Pearson's correlation dengan subjek penelitian penderita DM tipe 2 yang sedang rawat jalan di Poli Endokrin RSUD dr Saiful Anwar Malang periode Februari-Maret 2014. Didapatkan 100 sampel penderita DM tipe 2 (58\% wanita dan $42 \%$ pria) dengan rentang usia 29-90 tahun. Dari hasil penelitian ini didapatkan rata-rata usia pasien $\pm 59,11$ tahun, rata-rata Indeks Massa Tubuh $\pm 24,75 \mathrm{~kg} / \mathrm{m}^{2}$, dan rata-rata lingkar pinggang $\pm 92,46 \mathrm{~cm}$. Kesimpulannya adalah bahwa lama menderita DM tipe 2 tidak memiliki hubungan dengan status antropometri $(p>0,05)$.
\end{abstract}

Kata kunci : antropometri, diabetes mellitus, lama menderita.

\section{THE RELATIONSHIP BETWEEN THE DURATION OF TYPE 2 DM WITH ANTHROPOMETRIC STATUS ON OUTPATIENTS AT ENDOCRINE POLYCLINIC OF DR. SAIFUL ANWAR PUBLIC HOSPITAL MALANG}

\begin{abstract}
Diabetes Mellitus (DM) is a common health problem in the world. Type 2 DM patients have typical symptoms such as decreased body weight and anthropometric status at the beginning of suffering that can interfere with their quality of life. This study aimed to determine the relationship between the duration of type 2 DM with anthropometric status. This was an observational study using cross-sectional design method. Measurement and data collection were performed manually and tested using Pearson's correlation test. The population was type 2 DM outpatients at Endocrine Polyclinic of dr Saiful Anwar Public Hospital from February to March 2014. One hundred of type 2 DM patients (58\% female and $42 \%$ male) with age ranges 29-90 years were included as the study sample. The results showed that average age of the patients was \pm 59.11 years, mean of Body Mass Index was $\pm 24.75 \mathrm{~kg} / \mathrm{m}^{2}$, and mean of waist circumference was \pm 92.46 $\mathrm{cm}$. The conclusion is that the duration of type $2 \mathrm{DM}$ was not related to anthropometric status $(p>0.05)$.
\end{abstract}

Keywords : anthropometric, diabetes mellitus, duration.

* Program studi Pendidikan Dokter, Fakultas Kedokteran Universitas Brawijaya

** Dep. Ilmu Penyakit Dalam, Fakultas Kedokteran Universitas Brawijaya-RSSA

*** Dep. Ilmu Kesehatan Masyarakat-Kedokteran Pencegahan, Fakultas Kedokteran Universitas Brawijaya

$凶$ E-mail: sriandarini@yahoo.com 
Diabetes Mellitus (DM) merupakan masalah kesehatan yang sering ditemukan saat ini di dunia. Pada tahun 1980, DM jarang ditemukan di negara-negara berkembang. Bahkan di Cina prevalensinya hanya berkisar kurang dari $1 \%$ dari jumlah penduduknya. Hal ini sangat bertolak belakang dengan yang terjadi saat ini bahwa kebanyakan penderita DM merupakan penduduk dari negara berkembang. Dari data yang diperoleh pada tahun 2010 diperkirakan jumlah pasien penderita DM mencapai 360 juta orang dari seluruh penduduk dunia dan diperkirakan tahun 2030 jumlahnya meningkat sampai 439 juta orang. ${ }^{1}$ DM menyumbang angka kematian sekitar $5 \%$ dari seluruh penduduk dunia tiap tahun, dan 50\% dari kematian tersebut terjadi karena komplikasi kardiovaskular. DM sendiri merupakan gangguan metabolisme yang disebabkan oleh berbagai hal seperti peningkatan obesitas, kurang aktivitas fisik, kurang mengkonsumsi makanan yang berserat, merokok, dan tingginya lemak. Kurangnya aktivitas fisik dan faktor makanan sebagai penyebab terbanyak dari DM. Kedua faktor tersebut adalah penyebab terjadinya obesitas yang disebut sebagai salah faktor terbesar terjadinya DM. ${ }^{2}$

Klasifikasi DM terdiri dari DM tipe 1 atau disebut juvenile diabetes, DM tipe 2 atau diabetes pada masa dewasa, dan diabetes gestastional yaitu diabetes yang hanya terjadi saat kehamilan. Hampir $95 \%$ dari total penderita diabetes di dunia merupakan tipe $2 .{ }^{3}$

Menurut American Diabetes Association 2004, obesitas merupakan salah satu faktor risiko pada DM tipe 2. Obesitas adalah faktor risiko yang kuat dalam menyebabkan DM tipe 2 dan lebih dari dua pertiga pasien dengan DM tipe 2 mengalami

\section{Pendahuluan}

obesitas. Risiko meningkatnya DM lima kali lipat pada wanita dengan IMT $25 \mathrm{~kg} / \mathrm{m}^{2}$ dibandingkan dengan orang dengan IMT 22 $\mathrm{kg} / \mathrm{m}^{2}$. Risiko menjadi lebih tinggi mencapai 28 kali lipat dengan IMT $30 \mathrm{~kg} / \mathrm{m}^{2}$ dan 93 kali lipat dengan IMT $>35 \mathrm{~kg} / \mathrm{m}^{2} .{ }^{4}$

Penyakit sindrom metabolik seperti DM tipe 2 juga dapat terjadi pada individu yang non-obesitas tetapi memiliki resistensi insulin dan faktor risiko metabolik, terutama pada individu yang memiliki kedua orangtua yang diabetes atau keluarga inti maupun tingkat kedua yang diabetes. ${ }^{5}$

DM merupakan masalah kesehatan yang banyak dijumpai di dunia untuk saat ini termasuk Indonesia, dan menjadi ancaman serius bagi pembangunan kesehatan dan pertumbuhan ekonomi nasional. Organisasi Kesehatan Dunia (WHO) memperkirakan pada tahun 2030 penyandang diabetes di Indonesia sebanyak 21,3 juta orang. Kondisi ini akan menjadikan Indonesia menduduki peringkat ke-empat setelah Amerika Serikat, China, dan India di antara negara-negara yang memiliki penyandang diabetes terbanyak, dengan populasi penduduk terbesar di dunia. ${ }^{6}$

Indonesia merupakan negara berkembang yang memiliki banyak penduduk yang sebagian besar hidup dalam risiko terkena DM. Hal itu dikarenakan gaya hidup yang tidak sehat seperti lebih suka mengkonsumsi makanan cepat saji dan jarang beraktivitas fisik seperti olahraga. Dengan demikian, akan terjadi kenaikan berat badan atau Indeks Massa Tubuh (IMT) yang tidak ideal yang kemudian berujung pada obesitas yang merupakan salah satu faktor risiko DM. IMT yang ideal merupakan salah satu faktor pencegah terjadinya penyakit DM. ${ }^{7}$

$\begin{array}{crcr}\text { Lama menderita } & \text { DM juga } \\ \text { mempengaruhi } & \text { status } & \text { antropometri }\end{array}$ 
penderitanya karena pada kebanyakan kasus didapatkan penurunan berat badan secara mendadak yang sebelumnya mengalami obesitas bisa saja berubah menjadi underweight karena glukosa dalam darah tidak dapat dimetabolisme menjadi energi sehingga tubuh mengambil cadangan energi dari jaringan otot dan lemak. Lama kelamaan penderita akan mengalami penurunan berat badan. Untuk mengkompensasi hal ini penderita seringkali akan merasa sangat lapar sehingga menjadi lebih banyak makan (polifagi). ${ }^{8}$

Di negara-negara Eropa yang merupakan negara maju, status antropometri penduduknya cenderung mengarah ke obesitas. Obesitas di negara Eropa lebih dikarenakan gaya hidup yang kurang sehat seperti terlalu banyak mengkonsumsi makanan cepat saji, mengkonsumsi alkohol, dan makanan yang mengandung banyak kalori tanpa diimbangi dengan aktivitas atau olah raga yang cukup. Menurut laporan OECD (Organisation for Economic Cooperation and Development), di Inggris $24,5 \%$ orang dewasa menderita obesitas, di Irlandia 23\%, Malta $22,3 \%$, Islandia $20 \%$ dan Luxemburg 20\%. Sementara itu negara Eropa yang masuk dalam golongan cukup baik, di urutan pertama adalah Romania yang populasi obesitasnya $7,9 \%$, Swiss $8,1 \%$, Italia $9,9 \%$, Norwegia $10 \%$, Swedia 10,2\%. Di negara Asia jumlah obesitas tidak seperti pada negara Eropa, karena Asia merupakan tempat dari negara-negara berkembang. Secara tradisional, di negaranegara berkembang Asia orang-orang termiskin adalah orang-orang terkurus itu dikarenakan pekerjaan dan gaya hidup mereka yang menuntut kekuatan fisik. Selain itu, mereka lebih sering mengkonsumsi makanan tradisional, sedangkan di daerah perkotaan di negara berkembang Asia akan lebih banyak di jumpai orang-orang dengan status gizi obesitas yang disebabkan oleh pekerjaan dan gaya hidup mereka yang lebih sering duduk serta mengkonsumsi makanan cepat saji juga alkohol tanpa disertai aktivitas fisik atau olahraga yang cukup.

Khusus di Poli Endokrin RSUD dr. Saiful Anwar Malang, sebagai rumah sakit umum memiliki jumlah pasien DM yang banyak dan berasal dari berbagai daerah di Jawa Timur. Oleh karena itu, penelitian ini bertujuan untuk mengetahui hubungan antara lama menderita DM tipe 2 dengan status antropometri di Poli Endokrin RSUD dr. Saiful Anwar Malang.

\section{Bahan dan Metode}

\section{Rancangan Penelitian}

Jenis penelitian yang dipakai untuk penelitian ini adalah observasional untuk mencari korelasi antara lama menderita DM lebih dari 5 tahun dan kurang dari 5 tahun. Dengan pendekatan cross sectional study yaitu melakukan pengukuran atau pengamatan dalam sewaktu.

\section{Populasi dan Sampel}

Populasi dan sampel yang digunakan adalah penderita DM yang melakukan rawat jalan di Poliklinik Endokrin RSUD dr. Saiful Anwar Malang

\section{Populasi Penelitian}

Penelitian ini menggunakan dua jenis populasi yaitu populasi target adalah semua penderita DM, dan populasi terjangkau yaitu penderita DM yang menjalani rawat jalan di Poliklinik Endokrin RSUD dr. Saiful Anwar Malang.

\section{Cara Pengambilan Sampel}

Teknik sampling yang digunakan adalah teknik consecutive sampling, yaitu semua subjek yang memenuhi kriteria pemilihan, dimasukkan ke dalam penelitian sampai jumlah subyek terpenuhi.

Kriteria Inklusi dan Ekslusi 
Kriteria inklusi adalah semua pasien DM tipe 2 yang sedang rawat jalan di Poli Endokrin RSUD dr Saiful Anwar Malang. Kriteria eksklusi adalah pasien DM tipe 2 yang tidak dapat berdiri dan berjalan.

\section{Besar Sampel}

Besar sampel minimal pada penelitian ini ditentukan dengan rumus Slovin: ${ }^{9}$

Keterangan :

$$
n=N /[1+N(d 2)]
$$

$\mathrm{n}$ : besar sampel

$\mathrm{N}$ : jumlah populasi

$\mathrm{d}$ : tingkat kepercayaan $(95 \%=0,1)$

Dengan jumlah populasi penderita di Malang adalah 7.534 (Depkes Jatim, 2011), maka besar sampel adalah sebagai berikut :

$\mathrm{n}=\mathrm{N} /[1+\mathrm{N}(\mathrm{d} 2)]$

$\mathrm{n}=7.534 /[1+7.534(0,12)]$

$\mathrm{n}=7.534 /[1+75,34]$

$\mathrm{n}=7.534 / 76,34$

$\mathrm{n}=98,6900 \approx 100$

Jadi jumlah sampel yang digunakan dalam penelitian ini kurang lebih 100.

\section{Variabel Penelitian}

Variabel bebas adalah lama menderita diabetes mellitus. Variabel tergantung adalah Indeks Massa Tubuh (IMT) dan lingkar pinggang.

\section{Definisi Operasional}

1. Tinggi Badan : Diambil dengan kadaan pasien berdiri dan dilakukan pengukuran dalam $(\mathrm{cm})$.

2. Berat Badan : Diambil dengan keadaan pasien berdiri di atas alat pengukur berat badan kemudian dilakukan pencatatan dan pengukuran dalam (kg).

3. IMT: Hasil dari pengukuran Berat Badan $(\mathrm{kg}) /$ Tinggi Badan $\left(\mathrm{m}^{2}\right)$.

4. Lingkar Pinggang : Diambil dengan keadaan pasien berdiri kemudian dilakukan pengukuran lingkar pinggang dengan alat pengukur dalam $(\mathrm{cm})$.
5. Lama Menderita : Diambil dengan menanyakan langsung kepada pasien yang datang atau dari rekam medis pasien.

\section{Analisis Data}

Pengolahan data menggunakan Software Statistical Product and Service Solution (SPSS) for windows, menggunakan uji korelasi Pearson dengan taraf signifikansi $p<0,05$, disusun dan ditabulasikan kemudian disajikan dalam bentuk tabel ataupun grafik yang bertujuan untuk mengetahui hubungan antara lama menderita dengan status antropometri penderita Diabetes Mellitus $\geq 5$ tahun dan $<5$ tahun.

Hasil

\section{Karakteristik Responden}

Karakteristik responden yang diamati dalam penelitian ini yaitu jenis kelamin, status antropometri dan lama menderita. Hasil penelitian dijabarkan sebagai berikut.

Tabel 1. Data responden

\begin{tabular}{ll}
\hline Variabel & Mean \pm SD \\
\hline Usia (Tahun) & $59,11 \pm 11,41$ \\
\hline Jenis Kelamin (\%) & \\
\hline \multicolumn{1}{c}{ Pria } & 42 \\
$\quad$ Wanita & 58 \\
\hline Lama Menderita (tahun) & $7,3828 \pm, 499$ \\
\hline Berat Badan (kg) & $62,48 \pm 13,246$ \\
\hline Tinggi Badan $(\mathrm{cm})$ & $158,32 \pm 9,056$ \\
\hline BMl $(\mathrm{kg} / \mathrm{m} 2)$ & $24,75 \pm 4,446$ \\
\hline Lingkar Pinggang $(\mathrm{cm})$ & $92,46 \pm 9,858$ \\
\hline
\end{tabular}

Pada Gambar 1 diketahui bahwa seluruh responden telah menderita DM tipe 2 dalam kurun waktu $<5$ tahun yaitu sebanyak 44 responden, dan $\geq 5$ tahun sebanyak $\quad 56 \quad$ responden. 


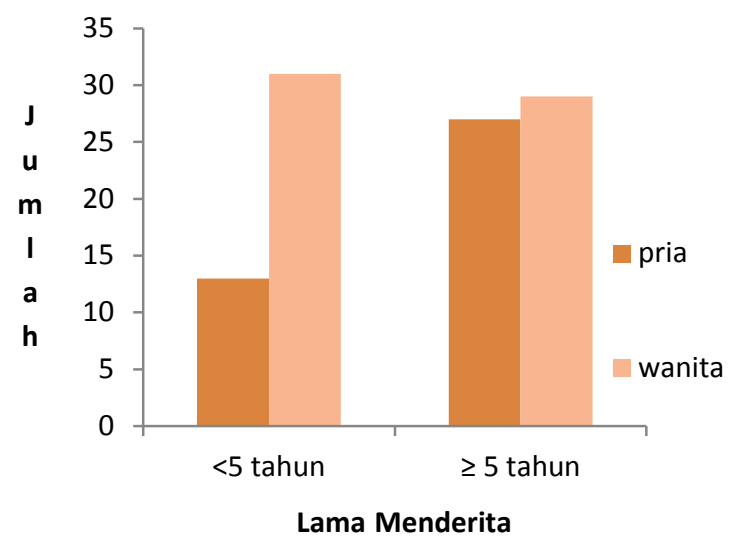

Gambar 1. Lama responden menderita diabetes mellitus tipe 2

Hubungan antara Lama Menderita dan IMT

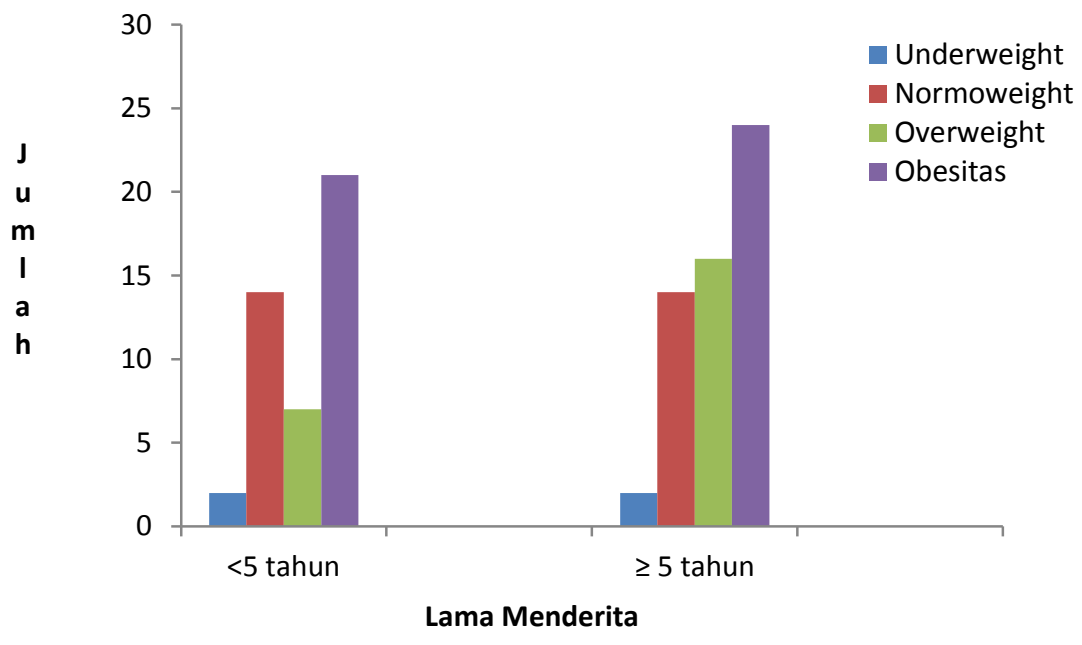

Gambar 2. Perbandingan IMT responden

Berdasarkan Gambar 2 diketahui indeks massa tubuh responden penderita DM tipe 2 dengan hasil $4 \%$ underweight, 28 normoweight, 23 overweight, dan 45 obesitas. Pada Gambar 3 dapat diketahui bahwa pada minggu pertama penelitian nilai rata-rata IMT pasien didapatkan $23,9 \mathrm{~kg} / \mathrm{m}^{2}$ dengan rata-rata lama menderita 8 tahun. Pada minggu kedua penelitian rata-rata IMT pasien didapatkan $27 \mathrm{~kg} / \mathrm{m}^{2}$ dengan rata-rata menderita selama 6,6 tahun. Pada minggu ke-tiga diketahui rata-rata IMT responden adalah $24,37 \mathrm{~kg} / \mathrm{m}^{2}$ dengan lama menderita DM rata-rata selama 7 tahun. Nilai rata-rata IMT pasien yang didapatkan adalah 24,57 $\mathrm{kg} / \mathrm{m}^{2}$ dengan lama menderita 10 tahun. Maka disimpulkan tidak terdapat hubungan yang bermakna antara lama menderita dan IMT $(p>0,05)$. 


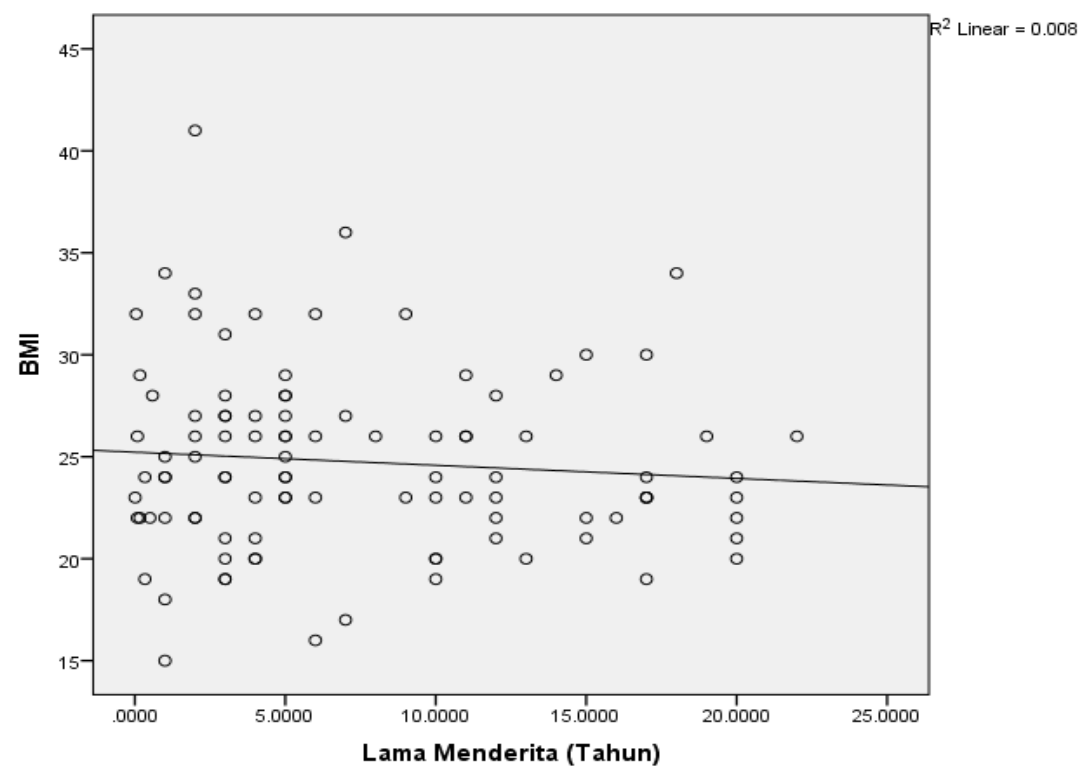

Gambar 3. Hubungan lama menderita DM dan IMT

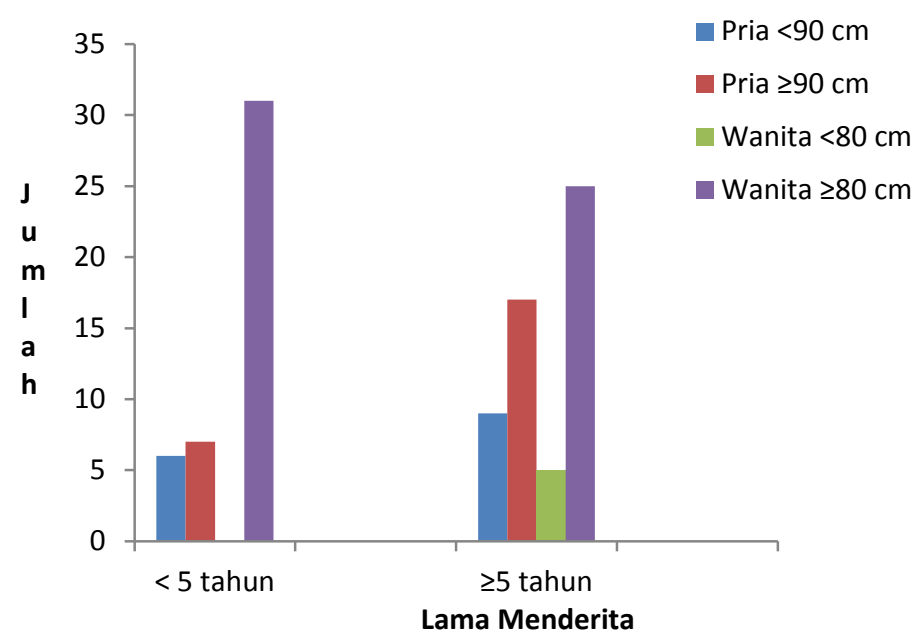

Gambar 4. Perbedaan lingkar pinggang responden

Hubungan antara Lama Menderita dan Lingkar Pinggang

Pada Gambar 4 ditampilkan hasil pengukuran lingkar pinggang dari seluruh responden (100 orang). Didapatkan sebanyak 30 orang memiliki lingkar pinggang $<30 \mathrm{~cm}$ dan 70 orang memiliki lingkar pinggang $\geq 90 \mathrm{~cm}$. Hasil pengujian pada 100 responden didapatkan rata-rata lingkar pinggang $\pm 92,46 \mathrm{~cm}$. Sehinggga tidak terdapat hubungan yang bermakna antara lama menderita dan lingkar pinggang $(p>0,05)$.

\section{Pembahasan}

Hubungan antara lama menderita dan IMT Hasil penelitiaan ini menunjukan IMT pasien rawat jalan yang menderita DM tipe 2 selama $\geq 5$ tahun dan $<5$ tahun didapatkan nilai rata-rata $\pm 24,75 \mathrm{~kg} / \mathrm{m}^{2}$. Hasil uji korelasi menunjukkan tidak ada hubungan yang 
bermakna antara lama menderita DM tipe 2 dengan IMT $(p>0,05)$.

Pada penelitian Helen dkk, dengan menggunakan 816 sampel yang meneliti perubahan IMT sebelum dan setelah di diagnosis DM tipe 2 diketahui sebelum didiagnosa DM tipe 2 terdapat kenaikan IMT 0,43 dan $0,71 \mathrm{~kg} / \mathrm{m}^{2}$ pertahun. Setelah didiagnosa DM tipe 2 diketahui penurunan IMT sebesar 0,61 dan 0,22 kg/m² pertahun. Jadi, sebelum diabetes ada peningkatan progresif dalam berat badan, dan setelah diagnosis, ada kecenderungan ke arah penurunan berat badan. ${ }^{11}$

Diabetes yang kurang terkontrol dapat menyebabkan penurunan berat badan melalui pengecilan otot, menurut sebuah laporan yang diterbitkan dalam "British Medical Journal." Hasil penelitian tersebut menemukan bahwa kekurangan insulin ditemukan dalam DM tipe 2 yang menurunkan sintesis otot dan meningkatkan kerusakannya. Namun, karena otot membuat hingga 36 persen dari berat ratarata seorang wanita dan hingga 45 persen dari berat badan manusia, pengecilan otot dapat menyebabkan penurunan berat badan melalui diabetes. ${ }^{12}$

Gejala lain dari DM tipe 2 yang dikaitkan dengan penurunan berat badan adalah sering berkemih. Bila sering berkemih dan tidak minum cukup untuk menggantikan cairan yang hilang, maka akan mengalami dehidrasi. Intensitas berkemih meningkat pada diabetes, karena ginjal harus bekerja lebih keras untuk menyaring kelebihan glukosa. Peningkatan glukosa dalam urin akan menarik cairan dari tubuh. Ketika kehilangan glukosa melalui urin serta akan kehilangan kalori yang dapat menyebabkan penurunan berat badan. ${ }^{12}$

\footnotetext{
Hubungan antara Lama Menderita dan Lingkar Pinggang

Pada penelitian ini didapatkan lingkar pinggang pasien rawat jalan yang menderita
}

DM tipe 2 selama lebih dari 5 tahun dan kurang dari 5 tahun yaitu rata-rata $\pm 92,56$ $\mathrm{cm}$. Berdasarkan uji korelasi Pearson diketahui bahwa tidak ada hubungan yang bermakna antara lama menderita DM tipe 2 dengan ukuran lingkar pinggang $(p>0,05)$. Hal ini berbeda dengan penelitian dr. Archna Dambal dkk, yaitu adanya hubungan positif antara durasi diabetes dan rasio pinggang pinggul, serta korelasi negatif antara durasi diabetes dan lingkar paha dengan menggunakan 28 sampel, dan disimpulkan bahwa lama diabetes mellitus meningkat, parameter antropometri juga meningkat. ${ }^{13}$

Pada penelitian Mohan Anjana tentang distribusi lemak pada pasien DM tipe 2 yang menderita lebih dari 1 tahun dengan jumlah sampel 82 diketahui bahwa lama menderita tidak memiliki hubungan yang signifikan terhadap distribusi lemak di pinggang dan tidak ada perbedaan yang signifikan dengan status antropometri. ${ }^{14}$

Menurut penelitian Sanjeev Sinha dkk, tentang fungsi paru-paru pada pasien DM tipe 2 dengan korelasi pada antropometri dan komplikasi mikrovascular yang menggunakan 29 sampel menyimpulkan bahwa antropometri pada pasien DM tipe 2 tidak berhubungan dengan lama menderita DM tipe 2. Namun, lama menderita DM tipe 2 memiliki hubungan dengan fungsi paruparu dan penyakit komplikasi mikrovascular. ${ }^{15}$

Berdasarkan teori yang berkembang dan menurut banyak penelitian yang telah di lakukan di seluruh dunia bahwa pada awal menderita DM tipe berat badan atau IMT cenderung menurun karena pada penderita DM tipe 2, insulin yang dimiliki tidak cukup mencegah tubuh untuk memperoleh glukosa dari darah ke dalam sel-sel tubuh yang akan digunakan sebagai energi, ketika ini terjadi tubuh mulai membakar lemak beserta otot untuk menjadi energi. Lemak yang paling banyak diubah menjadi energi didapatkan di 
sekitar abdomen dan paha yang kemudian menyebabkan berkurangnya berat badan. ${ }^{12}$

\section{Kesimpulan}

Lama menderita DM tipe 2 tidak memiliki hubungan dengan status antropometri (IMT dan lingkar pinggang) pasien DM tipe 2 yang sedang melakukan rawat jalan di RSUD dr. Saiful Anwar Malang.

\section{Saran}

Perlu diadakan penelitian lebih lanjut tentang hubungan antara lama sakit dengan status antropometri pasien DM tipe 2 rawat jalan di RSUD dr. Saiful Anwar Malang dengan memperhatikan faktor-faktor yang bisa mempengaruhi hasil penelitian seperti status gizi pasien terdahulu, riwayat sakit terdahulu, riwayat sakit keluarga, pekerjaan, dan tingkat pendidikan.

\section{Daftar Pustaka}

1. Chen L, Magliano DJ, and Zimme, PZ. The Worldwide Epidemiology of Type 2 Diabetes Mellitus-Present and Future Perspectives. Nat Rev Endocrinol. 2011; 8:228-236.

2. Holt T, Kumar S. $A B C$ of Diabetes. $6^{\text {th }}$ Edition. Chicester: Wiley-Blackwel. A John Wiley \& Sons, Itd. 2010.

3. National Institute of Health. U.S. Department of Health and Human Services. Diagnosis of Diabetes and Prediabetes. NIH Publication No. 124642. (2012).

4. Soegondo S. Diagnosis dan Kalsifikasi Diabetes Mellitus Terkini. Dalam: Soegondo $S$ dkk, (Editor). Penatalaksanaan Diabetes Mellitus Terpadu. Jakarta: Penerbit FKUI. 2005.

5. (ADA) American Diabetes Assosiation. Diagnosis and Classification of
Diabetes Mellitus. Diabetes Care. 2012; 35 Suppl 1:S64-71. doi: 10.2337/dc12s064.

6. Dinas kesehatan Provinsi Yogyakarta. Diabetes Mellitus Terus Meningkat. (Online).2012.http://dinkes.jogjaprov.go .id/berita/detil_berita/58-kasus-

diabetes-terus-meningkat.

7. Lifescript. At Risk Diabetes. (Online). 2012.http://www.lifescript.com/health/ce nters/diabetes.aspx.

8. Medica Store. Diabetes Mellitus. (Online).2011.http://medicastore.com/p enyakit/135/Diabetes_Mellitus.html.

9. Notoatmojo S. Metodologi Penelitian Kesehatan. Jakarta: PT. Rineka Cipta. (2002). P.136.

10. Miftahul A, Tatik M, Isworo JT. Hubungan Indeks Massa Tubuh (IMT) dengan Kadar Gula Darah Penderita Diabetes Mellitus (DM) Tipe 2 Rawat Jalan Di RS Tugurejo Semarang .2013.

11. Helen CL, Wiliamm CK, Robert LH. Changes in IMT and Weight Before and After the Development of Type 2 Diabetes. 2001.

12. Livestrong. Unxplained Weigt Loss with Diabetes. (Online). 2013. http://www.livestrong.com/article/44041

3-unexplained-weight-loss-withdiabetes/.

13. Dambal A, Herur A, Padaki S, Pati SI, Manjula R, Chinagundi S, Ankad R. The Correlation of the Duration of Diabetes with Anthropometric Indices in Type-2 Diabetes Mellitus. Journal of Clinical and Diagnostic Research. 2011; 5(2):257-259.

14. Anjana M, Sandeeo S, Depha, Santhakrisnan K, Vimalesmarani, Farooo S, Mohan V. Visceral and Central Abdominal Fat and Anthropometry in Relation to Diabetes in Asian Indians. Diabetes Care. 2004; 27(12):2948-53. 
15. Sanjeev SR, Guleria A, Misra RM, Pandey R, Yadav, \& Tiwari S. Pulmonary Functions in Patients with Type 2 Diabetes Mellitus \& Correlation with Anthropometry \& Microvascular Complications. Indian J Med Res. 2004; 119(2):66-71. 